\title{
Etiquette failure of the speech as a linguoecological problem
}

\author{
Olga Fomina ${ }^{1, *}$, Olga Potanina $^{1}$, and Iryna Shcherbakova ${ }^{1}$ \\ ${ }^{1}$ Don State Technical University, Gagarin sq., 1, Rostov on Don, 344003, Russia
}

\begin{abstract}
French word "etiquette" means "label". This concept is regarded as a philosophical, ethical, and linguistic and cultural notion. And the failure of etiquette in speech is a great problem of communication. As everybody knows, etiquette, including speech, is a set of rules of behavior that are associated with the external manifestation of attitudes to people. The external manifestation usually shows the inner essence of the relationship, which should naturally be mutually polite and kind. But the fact that etiquette has a national character, has its own cultural characteristics, takes it beyond the scope of one science. The study of speech etiquette needs special attention because it stands at the intersection of linguistics, cultural theory and history, ethnography, country studies, psychology, and other disciplines. Here, we will consider etiquette from the point of view of linguoecology as an obligatory component of linguoculturology.
\end{abstract}

\section{Introduction}

Language is a special world, that fertile soil, without which no culture in the world could be formed. It has long been known that it is with the help of language that a person is able to know himself and build relationships with the world around him. A person is surrounded by language space all his life. But at the same time, language is not only a means of communication and transmitting of information. It also represents the environment in which a person is formed and exists. A person lives inside the language, is constantly in it and experiences its influence.

The most important function of the language is to preserve culture and pass it on to the future generations. It is in this connection that language plays a very significant, even decisive role in shaping the personality and character of a nation or people. The relationship between culture and language can be considered as the relationship of the whole and its part. Language can be perceived as a component of culture or an instrument of culture (which is not the same thing), especially when it comes to a literary language or the language of folklore. However, language is at the same time Autonomous in relation to culture as a whole, and it can be considered separately from culture (which is constantly done) or in comparison with culture as an equivalent and equal phenomenon [1].

\footnotetext{
* Corresponding author: lelik8181@list.ru
} 


\section{Materials and methods}

In our work, we used various methods, including theoretical (study and analysis of special literature on the problem, classification, generalization based on the results of the survey); empirical (observation, questioning).

\section{The main part}

It is important that language is closely and directly connected with culture, since it develops in it and serves as its expression. On the basis of this provision, a new scientific direction emerged, which was called linguoculturology. This science has long been considered to be independent. But it is also a branch of linguistics. It is known that cultural studies examines the self-consciousness of a person in relation to nature, society, history, art, and other spheres of his social and cultural life. Linguistics studies the worldview that is displayed and recorded in the language in the form of representations of the language picture of the world. And linguoculturology has as its subject both language and culture, which are in close interaction, dialogue. Linguoculturology analyzes the mental, cultural and mental characteristics of representatives of different ethnic groups. And this allows us to identify the features of their cultural values, the specifics of the concepts of the material and inner world of a person.

Recently, most linguoculturological problems are considered through the prism of the intersection of disciplines. In our case, we analyze them from the point of view of language ecology. Many researchers traditionally include the concept of etiquette speech insufficiency in the linguoecological space.

If we take into account the generally accepted interpretation of etiquette as an established order of behavior, it is quite obvious that speech etiquette is actually a rigid type of communicative rules of behavior. Note how gradually and consistently specific forms of treatment from "high society" passed into everyday life and into modernity [5].

Speech etiquette refers to the system of speech behavior, the rules of live conversation and correspondence, how to use the language and its tools in a specific situation and environment. The first acquaintance with speech etiquette occurs before the year when parents show the child by example when to say "Hello", "bye", "thank you", "sorry". But these words are elementary formulas that become more complex with age and acquire new turns [7].

Without speech etiquette, it is impossible to imagine a full-fledged communication with friends, in a family circle or in a business environment. Since the development of speech etiquette and speech culture occurs gradually, it seems that this is a simple process - the family, kindergarten, school, by example or direct training assign the necessary norms and rules of communication to a person. But in fact, learning is closely intertwined with linguistics, history, culture, and psychology.

The sphere of speech culture includes the transmission of information plus linguistic ways of expressing emotions adopted by a particular people. So if in one culture it is customary to openly share emotions by talking about business, in others it is natural to be reserved, leaving the personal at home.

Speech etiquette consists of many ready-made formulas that make it easier to learn, making it simple and clear in which situation, which set of words is necessary.

Communication is divided into three blocks:

Beginning (introduction/greeting/introduction).

The Basis of the conversation (the essence and reason for the appeal or communication).

Final (final, final part). 
Regardless of the topic, the right conversation should be like this, otherwise it will be difficult for the interlocutor to tune in to the right mood, they may not understand what they want to convey or forget about the main idea of the conversation. Formulas include: words of politeness, greetings, farewells, and more [4].

The system of speech etiquette is on the following levels: vocabulary, phraseology (forms of address, special words, expressions); grammar (You with a capital letter); style (use of reserves selected speeches); tone (only quiet); orthoepy (full words, no jargon, slang or abbreviations); psychology (to hear the interlocutor, do not interrupt, do not interfere with someone else's communication).

The value of speech culture is so important that it is observed at all levels of communication, starting from the babble of a child and an adult, ending with business communication and even street chatter. Naturally, these will be different formulas.

The main function of speech etiquette is communicative. Help establish communication between the interlocutors, Express respect during the conversation, set the appropriate tone, emotional coloring with the help of speech tools. But do not underestimate other, unusual functions, such as contact-setting, appealing, voluntary, emotive, and others.

It is impossible to imagine the interaction of people without using the norms and rules of speech etiquette, whether it is familiar communication on the street, communication between a teacher and a student, conversations between business partners, etc. This is the selection of the correct pronouns, the choice of the necessary constructions, forms of words with the necessary information content and emotional coloring. The following diagram demonstrates the most popular spheres of using etiquette:

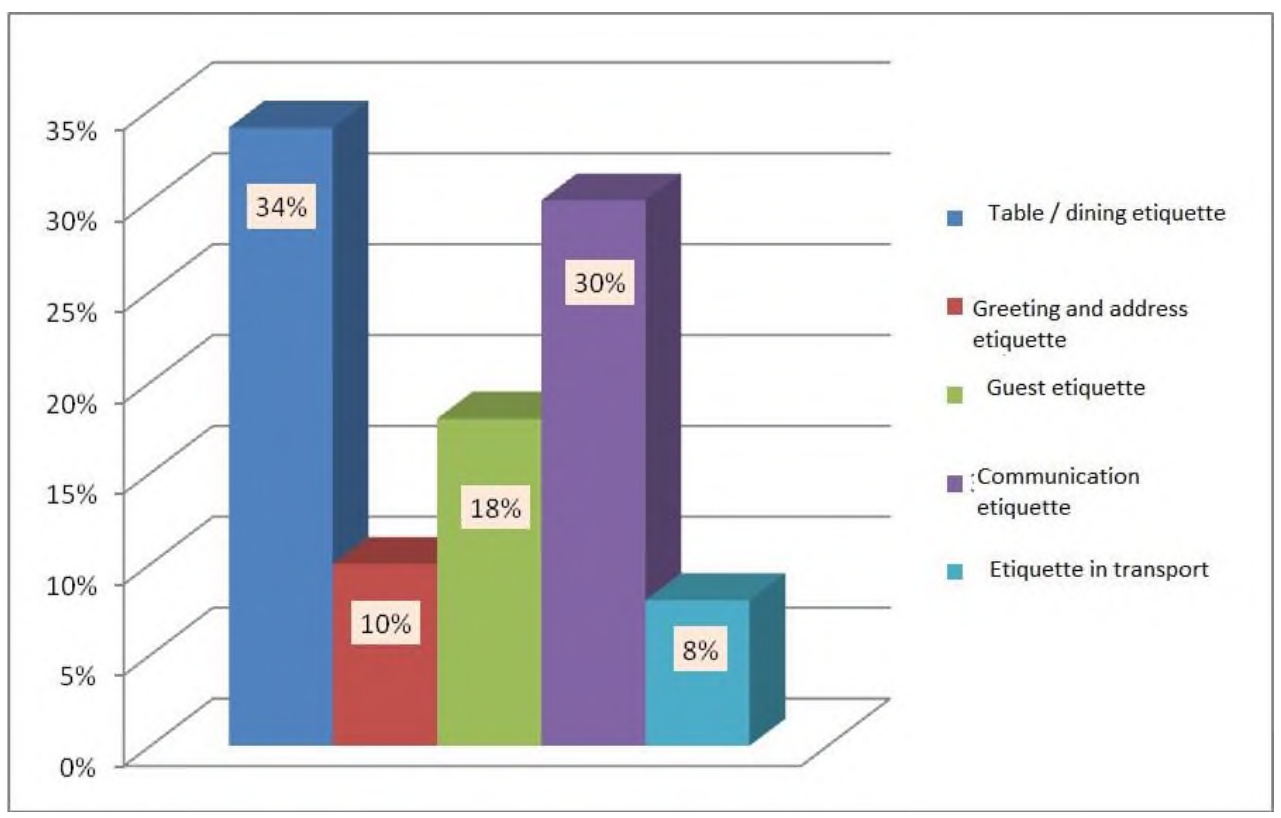

Fig. 1. The ratio of types of etiquette.

Speech etiquette as an important element of speech and behavioral culture contains at least two normative key semantic realities in the structure of its semantics: the language and social norm of politeness and behavior. Both are absolutely essential for successful communication. This requires both a specific speech situation and a generally harmonious social and cultural communication that corresponds to $\mathrm{n}$ In this regard, it is appropriate to recall the definition of speech ethics as the rules of proper speech behavior based on the 
norms of morality, national and cultural traditions [5]. It identifies such important value orientations as morality, national and cultural traditions that are mandatory for proper adequate behavior. Rules that may not be of a recommendatory, desirable, possible, selective, etc. Speech etiquette is traditionally associated with the field of speech ethics, since they have common, overlapping universal postulates of speech communication.

Mistakes in the choice of etiquette speech forms may be less noticeable, but no less pragmatically significant. So, for example, in a conversation with a person older than you (by age, rank, social status) from two formulas: "I advise you to read this book" and "in this book you will find a lot of interesting things" — of course, the second is preferable.

The level of ethical communication is significantly influenced not only by the communicative competence of the communicators, but also by their personal qualities.

Ethical and speech errors are more often committed by people who are characterized by short temper, irritability, straightforwardness, self-love, stubbornness, resentment, vindictiveness, partiality, pickiness, deceit, hypocrisy, unscrupulousness, aplomb, ambition, arrogance, arrogance, arrogance, self-love, vanity, braggadocio, neglect, brusqueness, egocentrism and some other negative emotions. Nevertheless, a critical attitude to their speech actions, self-control and self-discipline make it possible to minimize their negative impact on the culture of communication.

Etiquette norms can be broadly divided into three types: intra-cultural, subcultural, and cross-cultural. The whole set of national traditions and norms of behavior forms the etiquette of national speech behavior. The following criteria are always necessary to evaluate the rules of etiquette: the degree of formality / informality of communication, the partner's language passport (i.e. typical personality parameters that are guessed through speech - gender, age, social origin, occupation, profession, level of culture, etc.), the degree of relationship / dating, communication, situation, genre and the whole genre of speech, the level of culture of the partner [11]. The key category of etiquette seems to us to be the category of politeness, that is, the orientation of communication to preserve the dignity of the partner and respect for the addressee. The personal factor has a significant impact on the level of ethical communication. In this regard, internal self-control and self-discipline, especially for people who are egocentric, brusque, hot-tempered, minimizes errors of etiquette speech and cultural traditions.

For example, there is a whole set of rules on how to communicate with people with disabilities:

1.When talking to a person with a disability, speak directly to them, and not to their accompanying person or sign language interpreter, who are present during the conversation. (Note: we recommend using the term "sign language translator" instead of the official term "sign language interpreter" - similar to an English/French/other translator. language's). Do not talk about a person with a disability in the third person, addressing their accompanying persons, all your questions and suggestions should be addressed directly to this person.

2. When talking to a person who has difficulty communicating, listen carefully. Be patient and wait for him to finish the sentence. Don't correct or finish the sentence for him. Do not hesitate to ask again if you do not understand the person you are talking to.

3. When communicating with a person who does not see well or at all, be sure to name yourself and the people who came with you. If you have a general conversation in a group, do not forget to identify yourself and explain who you are currently addressing. Be sure to warn aloud when you step aside (even if you step away for a short time).

4.Do not rush to help a person with a disability if you are not asked to help. If you want to help, first ask if your help is needed. If you need it, ask what to do and how to do it, then proceed. If you don't understand, don't hesitate to ask again. 
5.When meeting a person with a disability, it is natural to shake their hand (if necessary, the left, not the right) - even for those who have difficulty moving their hand or who use a prosthesis.

6. When talking to a person in a wheelchair or a small person, position yourself so that your eyes and his are on the same level. It will be easier for you to talk, and your interlocutor will not need to throw his head back.

7.Address children and adolescents with disabilities by name, and adults by first name and patronymic, in the same way as other people without disabilities (on an equal basis, without condescension, guardianship, or patronage).

And the list can be continued.

Each country and nationality has its own rules of speech behavior. So for the Japanese, it is characteristic to recognize the infinite respect for the interlocutor, his family. They try to avoid direct denial or rejection. The Japanese partner will find hundreds of ways to say "no" without speaking directly. This is not a way to avoid responsibility or deceive a partner, it is a feature of the mentality and the desire not to offend a person by refusing.

The French tend to use ornate turns of speech, making communication colorful, rich in turns. They need clarity, clarity, and clarity in their conversations. They can't say "she smiled", they will definitely specify what kind of smile it is, kind, playful, with a hint of sadness or mockery. Although French has long been the language of diplomats, it is not easy to speak it in disguise.

For the English, it is typical to strictly adhere to etiquette in all areas of their lives. They show him a certain snobbery. If you do not adhere to most of the rules of behavior and conversation, the person will be perceived as a rude and ill-mannered gentleman. Without a culture of speech, you can't get what you want from a business partner or government employee. But it is necessary to choose the correct level of politeness (official, neutral and familiar style of communication).

It is necessary to pay attention to the peculiarities of Russian etiquette communication. First of all, it is sincerity, which is put in contrast to artificial politeness. This is a slight indifference to their own dignity and the dignity of the partner. A broad understanding of etiquette also includes the appearance that is appropriate in this situation. Etiquette necessarily correlates with appropriate actions in this situation.

In our opinion, the definition of speech etiquette in the interpretation of the Linguistic encyclopedia is the most complete from the point of view of semantics: "It is a system of stable communication formulas prescribed by society for establishing speech contact between interlocutors, maintaining communication in the chosen key in accordance with their social roles and role positions and relative to each other, mutual relations in official and informal settings" [1].

\section{Conclusion}

It is important to understand that the etiquette norms of speech also provide for certain rules for all participants in the speech act. The rules for the speaker include a friendly attitude to the interlocutor, appropriate politeness in this communication situation, modesty in selfassessment, selection of language tools in accordance with the chosen stylistic tone of the text, etc. In the rules for the listener, we find attentive listening, kindness, respect and patience towards the speaker, putting the speaker and his interests in the center of attention, timely reaction by action and verbally, etc.

Thus, we can conclude that the modern etiquette insufficiency of speech, in our opinion, is a phenomenon more social and cultural than linguistic. And it is connected, first of all, with an insufficient level of education, lack of morals and moral qualities. 
Hence, other moral-ecological and cultural "diseases" - loss of moral roots, loss of ethical principles, generation gap, the emergence of a special language for each generation, etc., which are also taken into account in the paradigm of environmental knowledge.

\section{References}

1. A.N. Alibaev, Norms of speech communication: speech etiquette Bulletin of the Osh state University 3-2, 238-241 (2016)

2. A.A. Batalov, Language and speech nature of speech etiquette tools Bulletin of the peoples ' friendship University of Russia, Series: Theory of language, Semiotics. Semantics 3, 79-85 (2016)

3. Z.M. Sarbasheva, Speech etiquette as a set of norms and stereotypes of communication Scientific almanac 11-1 (61), 202-204 (2019)

4. Kh.M. Kurdanova, Z.M. Sarbasheva, R.B. Kairova, Influence of speech etiquette on the formation of personality Human capital 6 (126),157-164 (2019)

5. L.V. Sokolova, Russian Proverbs and sayings about language and speech etiquette Innovative science 2, 6 (6), 162-166

6. O.A. Vasilieva, V.A. Smirnova, Yu.I. Ripatti, English etiquette Science, technology and education 6, 107-108 (2014)

7. D. Ashurova, N. Salomov, 2015 The national specificity of speech etiquette Science. Education. Personality 3, 22-25 (2015)

8. M.N. Shutova, S.S. Khromov, T.V. Nesterova, Expressives as a result of pragmatic transposition of vocatives, rogatives and etiquette speech acts AD ALTA: Journal of Interdisciplinary Research 10, 1, 201-209 (2020)

9. K.M. Hirnyak, Business etiquette in the personnel management

10. Scientific Messenger of Lviv National University of Veterinary Medicine and Biotechnologies named after S.Z. Gzhytskyj 15, 2 (56), 61-66 (2013)

11. K.Yu. Dyakova, Compliment as an element of speech etiquette in the aspect of intercultural communication, Bulletin of the peoples ' friendship University of Russia. Series: Russian and foreign languages and methods of their teaching 1, 41-46 (2015)

12. O.I. Vorobyova, Tras-kulturnye etiquette norms of modern communication, Collected papers: The First International Conference on European Conference on Language, Literature and Linguistics. Proceedings of the Conference 266-271 (2014)

13. M. Levkovich, Forms and methods of work on formation speech etiquette at the Russian language lessons, Collected papers: The Youth of the 21st Century: Education, Science, Innovations. Proceedings of the International Conference for Students, Postgraduates and Young Scientists Vitebsk. VSU named after P.M. Masherov 299300 (2014)

14. N. Formanovskaya, I.communication theory and speech etiquette, Russian language abroad 1 (218), 49-55 (2010)

15. A.Yu. Ponomarenko, Combinatorial analysis of english language speech etiquette units, European Researcher 12-2 (37), 2191-2196 (2012)

16. N.N. Bolotova, International business ethics, Youth and science 1, 237 - 240 (2012) 